\title{
Els contes de la primera època d'El Mole: aproximació a un material folklòric de principi del segle XIX
}

\author{
Carles J. Barquero Genovés \\ Universitat de València \\ cj.barqueroiı@gmail.com
}

RESUM

El diari El Mole, fundat a la ciutat de València l'any I837, constitueix l'exemple més antic de premsa regular escrita en llengua catalana. Malgrat que les motivacions del seu redactor principal, Josep Maria Bonilla, no van ser en cap moment culturals sinó polítiques (sobretot difondre la ideologia liberal $i$ anticarlina), sovint va utilitzar per al seu propòsit petits contes tradicionals d'origen folklòric per explicar o il.lustrar als seus lectors moltes de les idees i actuacions que defensava. L'objectiu del present article és subratllar l'origen folklòric i tradicional de tots eixos contes, editar-los seguint criteris filològics actuals i posar-los en valor com una de les mostres més antigues, desconegudes i notables de la rondallística tradicional valenciana.

PARAULES CLAU

El Mole; premsa; contes; folklore; segle XIX

ABSTRACT

The newspaper El Mole, founded in the city of Valencia in I837, was the first regular publication to be written in Catalan. Although the motivations of its main editor, Josep Maria Bonilla, were solely political (especially the dissemination of liberal and antiCarlist ideology) and never cultural, he often used folk tales to illustrate or explain to his readers many of the ideas and actions that he defended. The objective of this article is to investigate the folkloric and traditional origin of all these stories, to publish them in accordance with current philological criteria and to highlight their value as some of the oldest, least known and noteworthy examples of Valencian traditional folktales.

KEYWORDS

El Mole; press; folktales; folklore; Igth century

REBUT: I/O2/2OI8 | ACCEPTAT: 30/O7/2018 


\section{El qui, el què i el quan}

El diari El Mole va traure a la llum el seu primer número a València, l'any I837. Li correspon, per tant, l'honor de ser la publicació regular escrita en català més antiga de tot el domini lingüístic. Com a impulsor principal (malgrat que no únic) d'aquesta publicació cal assenyalar l'escriptor Josep Maria Bonilla (València, I808-I880), llicenciat en dret, lletraferit i home d'idees liberals i anticarlines. Dins les pàgines d'El Mole, Bonilla es presenta sempre com a portador d'un discurs revolucionari i insurreccional, gens procliu a les concessions ni als discursos moderats o possibilistes. Tal com assenyalen Laguna i Ortega (I989), el perfil de Bonilla és el d'un romàntic idealista, més inclinat al discurs i a la gestualitat que a la praxi política. En consonància, el diari per ell impulsat, El Mole, actuà en tot moment com a portaveu de la consciència més crítica i maximalista de la revolució liberal.

Però Bonilla, tal com hem apuntat abans, no va ser l'únic redactor de la revista. En la seua tasca periodística l'acompanyaren dos escriptors més, Pasqual Pérez i Rodríguez (Pataca Grossa) i Josep Bernat i Baldoví (Garrofa). El fet que tots tres autors assumiren malnoms relacionats amb el món agrícola (també Bonilla, altrament dit $\mathrm{Nap}-\mathrm{i}-\mathrm{Col}$ ) indica un altre tret característic d'El Mole: el propòsit decidit de fer de la classe camperola el destinatari privilegiat del discurs, tot en una època en què el tercer estat començava a ocupar per primera vegada el protagonisme polític.

Precisament eixa voluntat de practicar un proselitisme més eficient, capaç d'arribar a les classes populars, va fer que els redactors es decidiren per l'ús del valencià; ${ }^{\text {I }}$ en paral-lel, la necessitat de difondre el missatge ideològic de forma més entenedora motivà la tria d'un llenguatge planer. En les pàgines d'El Mole sovintegen així els recursos didàctics i pedagògics: col-loquis entre personatges imaginaris, teatralitzacions, apunts humorístics. La doctrina s'encapsula en píndoles saboroses, i en aquesta línia tenen un paper fonamental els contes, que s'hi intercalen per a fer entendre de forma senzilla alguna situació política susceptible de ser criticada.

Convé matisar un fet, i és que la presència de contes sols se circumscriu a la primera època de les cinc que va conéixer la revista, freqüentment prohibida i segrestada pels seus continus atacs al poder i a l'Església. Curiosament, i segons hem comprovat, a partir de la segona època (que s'enceta el I840) els contes, talment com altres recursos didàctics, hi desapareixen quasi per complet. És per això que el nostre article circumscriu l'àmbit d'estudi a la primera època de la publicació (del febrer a l'agost de I837). ${ }^{2}$

I Com assenyala Balaguer (I988), la necessitat urgent de fer proselitisme entre els llauradors era motivada pel fet que aquests s'havien mostrat al llarg de la història recent com una classe social molt progressista i activa contra les arbitrarietats de l'antic règim. A més, cal recordar que els llauradors podien engrossir les files carlines.

2 Treballem en tot moment amb l'edició facsímil editada l'any I993 per Edicions París-València (3 volums). 
Els contes de la primera època d'El Mole: aproximació a un material folklòric...

\section{Classificació tipològica}

Malgrat tot, veiem més clarament l'adscripció popular i folklòrica dels contes d'El Mole quan els apliquem el tamís del sistema de classificació temàtica ATU (Uther 2004):

- Quatre contes $(2,4,5$ i 8$)$ tenen com a motor algun cas de confusions lingüístiques degudes habitualment a la convivència, laminada i diglòssica, entre castellà i valencià, cosa que encaixa amb el tipus ATU I699 Misunderstanding Because of Ignorance of a Foreign Language. ${ }^{3}$ A part, el conte 8 es pot adscriure a ATU I807 The Equivocal Confession i el 4 a ATU I820 Bride and Groom at Wedding Ceremony. ${ }^{4}$

- Molts relats es basen en el concurs d'un personatge caracteritzat com a fava o babau, habitualment el clàssic llaurador o pep, ingenu i aliè als avanços del progrés (conte I3). Un clar exemple n'és la història del burro (7), que encaixa amb ATU I682 The Horse Learns Not to Eat. Però el protagonista molt sovint enganya: de vegades sols aparença ser estúpid quan en realitat amaga una gran perspicàcia. És el cas del conte 6, ATU I777A* I Can't Hear You, i dels números 3 i I2. Ben al contrari: el que sembla espavilat pot resultar ser ximple (II). La intel-ligència, l'enginy, té un paper bàsic en les històries relacionades amb la figura de l'anomenat Clever Man (ATU I525-I639), tòpic dins el qual podríem encabir els contes I, 3, 9, I2 i I5.

- Per acabar, resten fora dels conjunts anteriors tres contes: pel que fa al Io, sí que encaixa plenament amb el tipus ATU i365C The Wife Insults the Husband as Lousy-Head; 5 sobre el I6 i el I4, no hem sabut relacionar-los amb cap motiu folklòric dels arreplegats en les classificacions a l'ús.

\section{Importància del corpus de contes d'El Mole}

Tradicionalment, els estudiosos de la literatura catalana assenyalen un hiat tràgic entre el Segle d'Or de la literatura valenciana i els primers vagits de la Renaixença. Aquest espai de tres segles dibuixa un pont trencat entre l'edat mitjana i la contemporània. Així, podem veure un forat significatiu entre Timoneda, a qui Beltran anomena "primer folklorista valencià» i les primeres tentines de Martí Gadea, datables ja a finals del segle XIX.

Vists des d'aquest punt de vista, els contes d'El Mole presenten una importància extraordinària. Atenent la seua data de publicació (I837), resulten anteriors en molts anys a les primeres compilacions valencianes de Martí Gadea (I89I), i fins i tot a recerques folklòriques tan antigues com les de Milà i Fontanals (I853), Terenci Thos i Codina (I866) o Antoni M. Alcover (I896). En definitiva, il.luminen tènuement un camí fosc i, en la mesura que contes de transmissió oral, les seues

\footnotetext{
3 Sobre el conte 5 , fem notar que en trobem un de ben paregut a Menages i Monjo (2007: I86). 4 Atenent a la tipologia que Joan Borja (20I3) fa dels contes basats en malentesos lingüístics, podem classificar els quatre d'aquest apartat del mode següent: en el tipus $a$ (un personatge entén malament un altre que s'expressa en una llengua estrangera), els contes 2, 4 i 5; en el tipus $i$ (un personatge no entén un altre a causa de parlar en un argot), el conte 8 .

5 Afegim que Hernández Fernández (2010: 204) cataloga un conte exactament igual que el Io a Múrcia.
} 
arrels arriben probablement a tradicions molt anteriors al segle xix. D'aquesta manera, i encara que involuntari, el modest treball dels redactors d'El Mole com a folkloristes ens resulta impagable.

\section{Criteris de selecció i transcripció}

Hem incorporat a aquesta antologia tots els textos que, publicats dins de la primera època d'El Mole, presenten una tipologia narrativa. D'entre ells hem descartat només un cas, «El home invisible». Malgrat que el mite de l'anell màgic beu en fonts folklòriques molt antigues (ATU 560 The magic ring), creiem que aquest relat conté tres característiques que el distancien del conte tradicional i l'ancoren als trets propis d'una obra de creació contemporània: en primer lloc, el seu caràcter episòdic, similar al de les novel-les per entregues del XIx; en segon lloc, l'origen vuitcentista dels gèneres de què es nodreix (el relat costumista, la naixent novel-la de ciència-ficció i la sàtira política de tipus al-legòric); finalment, la voluntat d'estil, que resulta molt més marcada que en els altres relats. ${ }^{6}$

Sobre la transcripció, hem optat per mantenir la forma ortogràfica original, ja que considerem que la castellanització gràfica que exemplifiquen els textos aporta informació valuosa sobre la subordinació diglòssica pròpia d'aquesta època. Com a única excepció a aquesta norma de fidelitat a l'original, i sols per motius de claredat, hem decidit regularitzar mínimament tres aspectes: alguns casos d'apostrofació en què la segmentació de paraules es veia afectada (caixí = que així), el cas de les preposicions compostes com a i per a (en lloc de coma i pera) i, finalment, l'eliminació de l'accentuació innecessària en els monosílllabs $a, o$.

Per a una major comprensió del text, hem optat també per regularitzar la distribució en paràgrafs i, sobretot, les convencions tipogràfiques (ús de majúscules, signes de puntuació, cursiva i abreviatures). Sobre la disposició formal dels textos, per a ajudar a sistematitzar-los i estudiar-los hem cregut convenient dotar-los de tres elements: un número, un títol que no tenien en l'original i, finalment, unes breus coordenades que ubiquen cada conte dins el número corresponent d'El Mole. Sobre el títol, en tant que element extratextual, l'incloem entre claudàtors; sobre el número, segueix l'ordre cronològic en què cada conte va ser publicat en la revista.

Hem regularitzat també les convencions gràfiques relatives als diàlegs i a les frases citades literalment. Cal tenir en compte que, per la seua naturalesa, el sussuït i l'acudit es plasmen en textos de molta agilitat narrativa i conversacional. A aquest efecte, hem optat per reproduir el diàleg amb un guió situat abans de la participació de cada personatge.

Ja al final de cada conte afegim una frase breu que relaciona cada història amb la intenció ideològica que l'autor o autors buscaven amb la seua inclusió. Cal assenyalar que, en la mesura que Bonilla i els altres redactors treballaven sobre molts sobreentesos, algunes d'aquestes moralines no apareixen en l'original. Hem tingut, per tant, la necessitat de «reconstruir-les» amb una breu explicació de collita pròpia. En tot cas, les hem consignades sempre al final de la transcripció de cada

6 La voluntat d'estil està tan marcada que «El home invisible» és l'únic conte d'El Mole al qual la crítica atribueix un autor clar partint dels seus trets estilístics: Josep Bernat i Baldoví. Vegeu Bordería et alii (2004: 67). 
conte i indicant en tot moment si es tracta de manlleus originals del text o d'aportacions pròpies.

Veiem, doncs, que, d'igual manera que en els exempla medievals, la persona que escriu ix sovint del discurs per fer petites digressions en forma de conte que li permeten d'explicar de forma més didàctica les seues idees. D'aquest breu text que fa de pont entre el conte i el text matriu n'hem dit aplicació: l'autor hi recorre per explicar la relació entre paràbola i doctrina i relligar, de pas, amb el cabal principal del discurs. Hem cregut que, a banda de presentar els contes de forma individualitzada, fora bo fer un breu inventari d'aquestes aplicacions que els nugaven, com articulacions, a la intenció ideològica a la qual se subordinaven. D'aquesta forma, el material literari resta aillat però alhora contextualitzat en el producte periodístic per al qual l'autor el va fer servir.

\section{Edició dels textos}

\section{I. [El savi d'Atenes]}

El Mole, Ia època, Ir volum, núm. 2 (9 de febrer de i837): 32.

Un tio meu, que tot hu andevinaba perque tenia una botifarra baix la llengua, ${ }^{7}$ contaba que un sabio molt docte aconsellaba als ateniensos antics que així com llauraben y treballaben les terres en rosins, també podien llaurar en burros. Pero habentli contestat que els burros no eren bons pa este treball digué el sabio:-Que importa? Tambe trien pa gobernar la república chefes tan poc aptes pa manar com els burros pa llaurar la terra.

Aplicació (extreta de l'original): «En que li sembla asó a lo que pasa en España? En los pollins de cuatre potes y en los burros de dos cames».

\section{2. [El tio Tòfol i Vaoret]}

El Mole, ia època, Ir volum, núm. 3 (II de febrer de I837): 35.

Diu que era un pare, y este pare tenia un fill, y este pare y este fill eren llauradors, y este pare sempre estaba malaltús, y este fill era un archent viu ${ }^{8}$ que se'n pasaba de ralla perque a cada pas anaba a tamborinades ${ }^{9}$ en uns y atres, de modo que el pobre del pare no tenia prou cuèns ${ }^{\mathrm{IO}}$ per a pagar barbers ${ }^{\mathrm{II}} \mathrm{y}$ medisines als que son fill descalabraba, pues al ú li fea un trenc en la calavera, al atre li posaba els nasos chorrant sanc, al atre el deixaba coixo de una pedrada; en fi, era un diable, un fill de Satanás.

7 Tindre una botifarra baix la llengua: Desconeixem l'expressió i no l'hem trobada en cap diccionari. Sembla, pel context, que siga sinònim de tenir molta facilitat de paraula.

8 Ser un argent viu: «No estar quiet, moure's contínuament» (DNV).

9 Tamborinada: «Colp fort» (DNV).

Io Cuens: Diners.

II Recordem que en aquesta època els barbers feien tasques senzilles de cirurgia com sagnies, talls o embenats. 
Vivia el pare en una barraca prop del camí de Chesús. Susuí pues un dia que la malaída criatura, no sé com, s'enredrá en un pixavinet ${ }^{\mathrm{I} 2}$ y de llargues a curtes li embocá un cudòl sanser en lo cap, de modo que el deixá mich estomordit. Aon fon el cas no hu se, solament dic que se trovaen a tir dos aguasils, que es chent que sempre está a punt y amaneix aon manco la esperen, y sino que hu diguen els pobres fematers, que no guañen prou per a sustos cuant rasquen la terra dels carrers y per art de Satanás se veuen al costat sinse saber còm els menistres de la chustisia, com ells se diuen, els membres del tribunal...

Pero ¿aon vach a parar? Perdonen vostedes y núgue el cap... Lo sert es que Vaóro (aixina li dien a aquella malaventura de chic) aná aquella nit a dormir a Sent Arsis. ${ }^{13}$ El primer pas fon buscar qui tinguera ingüent responsable per a que la chustisia no treballara de váes. El anchelet digué plorant que vivia en lo camí de Chesús y que a son pare li dien Tòfol. Sobre la marcha se destiná un notari acompañat d'un escribent per a pendre declarasions al pare, que lo que manco ${ }^{14}$ pensaba era en notaris y estaba aguardant al seu Vaoret. Chustetament aquell dia habia enviat a cridar a un dotor perque se trovaba pichor y se pensaba que no tardaria, cuant de repent se veu entrar per la porta dos homens ben vestits, el ú en un potracol $^{15}$ baix lo bras.

El bon tio Tòfol cregué que era el dotor y un praticant, y cuant viu que el chove del potracol trea de la bolchaca un tinteret de cuerno y s'asentaba a escriure posant el potracol damunt del chenoll, se calá que anaba a escriure una resepta. Entonses el notari (perque eren el notari y son escribent), el notari que per desgrasia era churro $^{16}$ y no guipaba sixquera una paraula de valensiá, encomensa son interrogatori en esta forma: — ¿Qué tiene usted? El pobre Tòfol sempre cregut que aquell era el dotor, li respongué: - Siñor, yo tinc tremolins ${ }^{17}$. —Escriba $V$. —digué el notari al escribent-que el señor tiene tres molinos: con esto ya hay para empezar el espediente.

Aplicació (extreta de l'original): «¿Y asó a qué vé, siñor Mole? —No ve tan fora del cas, fill de la meua anima. Tots els españols son tios Tòfols, tots parlen en una llengua, y els entenen en atra.»

\section{3. [El pare Mulet, lleter]}

El Mole, ia època, Ir volum, núm. 7 (25 de febrer de i837): Io8.

Aquell pare Mulet era un home molt particular, d'eixos que n'entren tres en lliura y a lo millor tenia unes ocurrensies molt chistoses..$^{18}$ Un dia (¿están vostedes?) un dia ixqué del convent a les sinc del matí en lo llec que l'acompañaba, y encara no

I2 Pixaví: «En els pobles dels voltants, natural o habitant de València, Castelló, Gandia i d'altres ciutats.» (DNV) «Home presumit, sobretot en el vestir» (DCVB).

I3 Sant Narcís: Presó de l'època situada a l'inici del carrer del Salvador, a València.

I4 Manco: Menys. Possible italianisme molt caractéristic del valencià.

I5 Patracol: «Paperassa, especialment conjunt de documents exigits per l'Administració pública.» (DNV). La paraula prové de la deformació popular, per metàtesi, de protocol, mot que habitualment designava els volums grossos en què els notaris anotaven les seues actes. I6 Xurro: Persona provinent de territoris castellanoparlants.

I7 Tremolins: Calfreds (DCVB).

I8 El pare Francesc Mulet (Sant Mateu, I624 - València, I675) fou un escriptor satíric valencià que, després de la seua mort, esdevingué un personatge folklòric, protagonista habitual 
pasaba un ánima per lo carrer y aquell ent singular, tot un pare mestre chubilat, escomensa á cridar: - A la leche! A la llet! Leche de cabra! El llec se quedá fet un pavís, ${ }^{19}$ mirántselo com qui veu fantasmes, y li digué: - Pare mestre, ¿Qué es lo que fa sa paternitat? ¿S'ha tornat loco? -Calla, moñicot ${ }^{2 \circ}$ (li contestá el pare Mulet) ¿Qui s'ha de pensar que a estes hores ha danar el pare Mulet cridant per lo carrer «A la leche, à la llet»? Y habent dit aixó comensá atra volta a cridar mes fort: - A la leche! A la llet! Leche de cabra!

Aplicació (elaboració pròpia): Molts polítics són com el pare Mulet: aparentment són respectables i seriosos i després es porten com xiquets: ploren i tenen rabietes quan no obtenen el que volen; semblen incorruptibles i cedeixen a qualsevol estúpida temptació o a la lluentor dels diners.

\section{4. [Sí, pare!]}

El Mole, ia època, Ir volum, núm. 7 (25 de febrer de I837): IIo.

Fon el cas (lo que es del poble aon susuí no me'n recordé a fe de hòme formal) que anaren a casarse dos, per supost hòme y dona, davant de la Santa Iglesia, sircunstansia que per desgrasia no s'observa molt asovint. El pae retor era també paisá del notari a qui ya coneixen nostres lectors ${ }^{21} \mathrm{y}$, cumplint en lo seu ofisi, preguntá al novio: —¿Quiere V. recibir a fulana por legítima esposa? [...] El novio, molt serio y estirat, li respon: - Si pare. - ¿Como si pare? Eso V. se lo verá después. Ahora solo digo si la quiere V. por mujer. -Si pare. -Pero venga V. acá ¿Qué no sabe V. que eso que dice no es esencia del matrimonio, pues hay muchos que no tienen hijos y sin embargo...? -Si pare. -Dale bola con si pare, si pare; ya me voy yo enfadando, y sepa V. que aquí no se viene a burlar con el sacramento. Si viene V. a eso, vaya V. mucho con Dios, que no estoy para fiestas.

La cosa anaba de mal ull, ${ }^{22}$ sols que el escolá, que había estudiat fransés en la universitat de Patraix, ${ }^{23}$ penetrá la dificultat y li digué al pae retor: -Desimule osté, pá retor, que este tros de bajoca vol desir «si, padre», casina hablamos musotros, y no dice ná de parir. Entonses el bon retor se clavá les ulleres y seguí. - Ego vos conjugo, in nomine patris etc etc etc. Y se'n anaren tots tan contents com el dia del atac de Siete-aguas. ${ }^{24}$

Aplicació (elaboració pròpia): Alguns esperen que el govern puga parir alguna cosa, però el govern promet molt i no pot parir res.

d'anècdotes i sussuïts. La seua fama més notable, com es comprova en aquest conte, és la d'haver estat un home ocurrent, transgressor i un tant bròfec.

I9 Pavís: Beneït. A Joaquim Martí Mestre (2006: 408).

20 Monyicot: «Jove que té el comportament d'un xiquet» (DNV).

2I Es refereix al protagonista del conte 2, és a dir, parla d'una persona de llengua castellana. 22 Anar de mal ull: anar pel mal camí.

23 Patraix era en aquesta època un poble pròxim a València, i conegut per la seua escassa població i extensió. La referència a Patraix té ací, per tant, un sentit caricaturesc.

24 Possiblement es refereix a l'atac frustrat del general carlí Forcadell al poble de Setaigües, l'any 1837 . 


\section{5. [Tres paiportins i uns francesos]}

El Mole, ra època, Ir volum, núm. 9 (4 de març de I837): I44.

Anaben per lo camí de Morvedre tres llauradors escapats dels fransesos en temps de la guerra de Napoleó y se'n tornaben a Paiporta, d'aon eren. Prop dels Hostalets de Pusol veren a sinc ú sis gavachos de la guarnisió del castell, que venien capa Valensia. Els pobres pèps ${ }^{25}$ se donaren per perduts, pero ú d'ells, mes arriscat, digué als seus compañs: - No tingau pòr, que yo vos trauré a la banda de fora. ${ }^{26}$ Vach a parlarlos, que yo talle el franses lo mateix que si l'haguera parit. Y acostantse als soldats li diu al ú: —Vous parler franquais? —Oui, Monsieur. —Y qué tal? ¿Teniu bona cullita en vostra terra? - Je ne comprend pas. — ¿No veeu? —se chirá molt satisfet als atres llauradors- molt bona cullita tenen: no compren pá, es señal que pasten en casa.

Aplicació (elaboració pròpia): Segons El Mole, als francesos, acusats de connivència amb els carlins, se'ls tracta excessivament bé. Ja no pasten el pa «perque els españols els planten el forment, li'ls molen, feñen la farina, la pasten, la couen, els obrin la boca, els fiquen el pá y els menechen les barres» (cometes extretes de l'original).

\section{6. [Les sopes de pa]}

El Mole, ra època, Ir volum, núm. II (II de març de i837): I76.

Estaba un llaurador tallant lleña dalt d'una montaña y un atre nugant garbons a la banda de baix. Fea un aire molt fort y acostantse l'hora de dinar, li preguntá el de baix al de dalt: - De quin pá vols que fasa les sópes, del teu ó del meu? El de dalt li respon: -Fesles del teu, que no t'entenc del aire.

Aplicació (elaboració pròpia): València pregunta a Madrid si arregla els seus problemes. Madrid respon que s'arreglen els valencians, que ells no entenen a causa de l'aire que fa. Se'n desentenen, doncs, de la seua part, igual que el llaurador del conte.

\section{7. [Un pobre burro]}

El Mole, ra època, Ir volum, núm. I9 (I3 d'abril de I837): 297.

Un home tenia un burro y el volia abear a no menchar. No li doná res y als huit dies, el pobre burro a descansar al riu. ${ }^{27}$ «Que desgrasiat soc! —digué el amo-. Quin burro tan burro! Ara se li ocurrix morirse, que ya el tenia abeat a no menchar!».

Aplicació (elaboració pròpia): L'autor suggereix que el burro són els ciutadans i l'home el gran home, potser algun governant.

25 Pep: «Pagès rústec o ignorant» (DCVB).

26 Traure a la banda de fora: Expressió desconeguda que no hem trobat enlloc. Pel context, traure algú d'una situació apurada.

27 Anar a descansar al riu: Eufemisme per morir. 


\section{8. [El confessor del Grau]}

El Mole, ra època, Ir volum, núm. 24 (30 d'abril de I837): 377.

¿Sap vosté que la chent menuda bolichera ${ }^{28}$ del Grau (no dic tots, sino la chent del bronce $)^{29}$ tenen un dicsionari tan particular que no'ls entendrá el mateix dimoni?

Diu que una volta aná a confesarse ú de eixos que tenen fet coneiximent en les reixes de les alqueries del Cañamelar y Cabañal en los mesos del hivern, y saben per qué... S'achenolla davant del frare y escomensa: - Pare, m'acuse que ha entrat en una alquería de fulano y ha trovat dins uns plats, escurada y atres coses que tenen els amos damunt del escudeller per a cuant van al estiu, y tot hu he salvat. El confesor li digué: - Vamos, fill, d'aixó no tens que confesarte, perque al cap es una bona obra salvar les coses. Seguí el fadrí: - Pare, m'acuse que he salvat una pesa de roba. - Deixat d'aixó y confesa els teus pecats. - Si no tinc atra cosa que dir, tot son salvasions. - Pues Deu te beneixca, ánima predestinada, vade in pace.

Entrá en seguida atra criatura de dotse añs, y vinga salvar, y vinguen salvasions, que el pobre confesor se fea creus al vore una virtut tan heroica, y tal inosensia de costums en uns bolichers. Aplega el tercer y lo primer que emboca ${ }^{3 \circ}$ es una salvasió de un rellonche... Entonses el pare ya escomensá a sospechar lo que podría ser alló, y per a mes asegurarse, li pregunta: —Digues, fill: ¿Y cuánt tems fa que has deprés a salvar? —Desde que tenia sinc añs, que m'amostraba mon pare y ma mare. —Y díguesme: ¿Qué es salvar? — ¿Pues que no hu sap vosté? —No. —Es que es... aixó... salvar. - Pero criatura, ¿Qué es salvar? -Es... es... alló que diuen... furtar.

Al ouir asó el pobre confesor s'alsa de la cadira fet un lluquet,,$^{3 \mathrm{I}}$ y escomensa a cridar davant de tota la chent que hi habia en la iglesia: _ ¿Que vinguen así tots els salvadors, que tornen a confesarse els salvadors, que encara no s'han confesat, que m'han engañat els salvadors... Y es mogué una broma que s'afonaba la iglesia. ${ }^{22}$

Aplicació (elaboració pròpia): L'autor aprofita l'equívoc lingüístic i es pregunta qui salvarà la nació. Suggereix, per tant, que aquell qui diu que la salvarà realment vol dir que hi furtarà tot.

\section{9. [El senyor Cardelati]}

El Mole, Ia època, 2n volum, núm. I (I de maig de I837): 7.

Cuant yo era chic coneguí a un italià que donaba remeis per a tots els alifacs ${ }^{33} \mathrm{y}$ malets, que es com si diguérem, donaba mides estraordinaries, y entre atres reseptes que tenia una era per a matar uns animalets casi tan apegalosos y ruins com

28 Bolitger: «Persona que pesca amb bolig».

29 Gent del bronze: «Perdonavides, pinxos, brivalls» a Joaquim Martí Mestre (2006: 287). 30 Embocar: «Dir a la cara» (DNV).

3I Lluquet: «Tros de palla o de cànem ensofrat que, quan s'acosta a una brasa, crema amb flama» (DNV).

32 Martí Mestre (2006: 489) parla d'aquesta peculiar utilització del mot salvar. «Els delinqüents practiquen a través del llenguatge una inversió dels valors socials, robar és vist per ells, no sense ironia, com una acció positiva. Als seus ulls, furtar alguna cosa és salvar-la, deslliurar-la de l'amo, i col-locar-la en lloc «segur» en les seues mans.

33 Alifac: «Mal físic que sobrevé amb els anys o que es patix a conseqüència d'una malaltia» (DNV). 
els facsiosos ${ }^{34}$. Anaben uns: -Siñor Cardelati, yo estic avivat de puses, ú de... ú de... - Bono, bono... presto quedarete libero. Vedete com si fa. Trea una caixeta en uns polvets, prenia un pesic, lin donaba al pasient y li dia:

Prendi la polvere,

apri la boca,

meti la polvere,

la chincha morta. ${ }^{35}$

Anaba el home ú la dona molt «si siñor», agafaba els animalets y vinga arruixada de polvere, però ells vius que vius, com els facsiosos que perseguix un cheneral, ú dos ú tres, que yo sé. Tornaben al italià: - Home, que el remey no aprofita, que n'hia mes que de primeries. — ¿Avete fato esto que yo he dicho? - Si siñor. - Pues, mio siñore, la proba é forte, il remedio probato. Si osté vede que se movent las chinchas é que corren, no lo creda, perque il remedio é probato.

Aplicació (elaboració pròpia): burla sobre la propaganda que fa creure que hi ha diners quan en realitat no n'hi ha i que els carlins han estat quasi derrotats quan no és cert.

\section{Io. [La dona de Pere Furietes]}

El Mole, ra època, 2 n volum, núm. 5 (23 de maig de I837): 75.

La dona de Pere Furietes era la dona de un marit, y li dia: -Pollós! —Mira, Senta, que ho pagarás. - Pollós! —Mira, dona, que’t mataré. —Pollós, més que pollós! —Mira que t'ofegaré. —Més que pollós! —Mira que t'agafe y te tire en la sequia. -Pues bien, pollós! Furietes l'agafa, l'alsa en pes y la fica hasta el coll en la sequia, que tenia bon toll. — ¿Calles? Mira que t'ofegue! —Pollós y repollós! —Senta, mira que vas a morir... - Repollós! —Mira que t'aplega l'aigua a la boca! —Po... glogloglo... llós... glogloglo... po... glogloglo... llós... glogloglo. — ¿Sí? Pues amòla’t! ${ }^{36}$ Y el tio Pere la afona dins l'aigua. ${ }^{37}$ ¿Y creuran els lectors amats que la bona de Senta pará per una friolera com eixa? ¡Caaa! Ya que no podia en la boca, trau les mans del aigua per damunt del cap y achuntant les ungles dels dits pulgars ó grosos, com qui mata un poll, li dia a son marit: —Pollós! Pollós! Pollós!

Aplicació (elaboració pròpia): El Mole és com la dona de Pere Furietes. Seguirà incomodant les autoritats malgrat totes les persecucions i censures que s'armen contra ell.

\section{II. [El matemàtic profund]}

El Mole, ia època, 2n volum, núm. II (i6 de juny de I837): I69.

Una volta estaben uns arquitectos acabant un pont molt gran y ample sobre un riu [...] y mentres li pegaben la última má, veren a un home mes serio que alt Mendisabal, $3^{8}$ que anava prenent mides y fent càlculs de una banda a atra del pont

34 Facsiosos: Carlins.

35 Sobre l'italià macarrònic de Cardelati, vegeu Borja (2013: 63).

36 Amolar-se: «Blair, fer molt de mal, produir dolor intensa» (DCVB).

37 En l'original, i segurament a causa d'un error d'impremta, aigui.

38 Juan Álvarez Mendizábal: President del Consell de Ministres i ministre d'Hisenda de I835 a 1836. 
sinse parlar una paraula per a un remei. Els arquitectos, al vore aquella aplicació y prosopopeya, ${ }^{39}$ cregueren seria un matemátic profundo, y acostantse li preguntaren en molta cortesía que qué li pareixia de aquella obra. El Arquimedes modern seguí encara un ratet mes considerant el pont en aire de importansia hasta que, encarantse als arquitectos, respongué en molta pausa y formalitat:-Me pareix que han fet vostedes molt be en fabricar el pont sobre lo ample del riu, perque si fora a lo llarc els costaria molt mes treball.

Aplicació (elaboració pròpia): Per a previndre la possible arribada de carlins a València s'estan cavant unes fosses al camí del Grau, però totalment inútils perquè les estan fent en paral-lel al camí.

\section{I2. [La volta del Tio Verderol]}

El Mole, ra època, 2n volum, núm. I6 (30 de juny de I837): 254.

Determinat el tio Verderol a anarsen a Rusafa, que com tots saben no està mes que un tir de bala de Valensia, se posa les alforches al coll y se n'ix per lo portal de Serrans, carrer de Molvedre avant. Al chirar cap a Moncada, encontra al seu amic Cagarnera, y li pregunta que aon anaba en les alforches unides. - A Rusafa vach, Cagarnera. — ¡Home! ¿A Rusafa per así y ve de Valensia? ¿Vosté sap lo que fa? —Si no ho sabera pronte aplegaria, però yo guañe mes en rodar.

Acabaren raons y el Verderol mou dretet a Moncada; d'allí s'amorra ${ }^{40}$ cap a Burchasot y Benimamet, pasa el pont de Manises y per Alacuás y Torriente ${ }^{4 \mathrm{I}}$ refila dret a la torre de Espioca. Per aon anaba pasant agarraba lo que li acomodaba dels camps, y ya portaba l'alforcha plena de sebes, alls tendres, ansisam, carchofes, rabens y de etc. etc.

D'Espioca, veense ya mes carregat que un diplomátic, mes que un ministre, s'emboca $^{42}$ dret a Silla ficanse en lo tripal ${ }^{43}$ lo que no li cabia en les alforches y a les nou de la nit aplegá a Rusafa. Se fica en casa una neboda y vénselo entrar en les alforches tan plenes, li digué: — ¡Tio! ¿D'aon ve tan carregat y a estes hores? -De Valensia. - Pues si fa ya una hora que han tancat el portal. ¿Aon s'ha ficat hasta ara? -Yo ixquí de Valensia al rompre el dia o al obrir els portals, y me n'ha vengut per Moncada, Benimodo, ${ }^{44}$ Alacuás, torre de Espioca y Silla. - Y podent vindre en sinc menuts, ¿Per qué ha gastat mes de catorse hores rodant per eixos trigos? ${ }^{45}$ — ¡Ay, neboda meua, Tú no m'entens! Si haguera vengut per lo camí recte no haguera agarrat ni un pàmpol, $\mathrm{y}$ pegant voltes $\mathrm{y}$ revoltes per sendes $\mathrm{y}$ camins forans, ${ }^{46} \mathrm{y}$ allargant el viache, mira com porte de plena la alforcha! ${ }^{47}$

39 Prosopopeia: «Afectació de gravetat» (DCVB).

40 Amorrar: «Posar els morros a qualque banda» (DCVB).

4I Torriente: En realitat Torrent o en castellà, Torrente. La forma utilitzada en el conte és de caràcter burlesc.

42 Embocar: «Girar una cosa amb la boca o sortida cap a cert lloc» (DCVB).

43 Tripal: «Pitrera, sina» (DCVB).

44 Possiblement error de redacció. On diu «Benimodo» hauria de dir «Benimànet».

45 Echar a alguien por esos trigos: «Ir desacertado y fuera de camino» (DRAE).

46 Camins forans: Camins de fora, llunyans.

47 En l'original, i segurament a causa d'un error d'impremta, aforcha. 
Aplicació (extreta de l'original): «Si els que mos porten cap a la llibertat y la felisitat anaren per lo camí recte, ya no quedaríen faccions ni fulleros; ya estariem allà. Pero rodant per camins torts y allargant el viache n'hia per a tots, y omplin millor les bolses.»

\section{I3. [Dos llauradors al teatre]}

El Mole, Ia època, 2 n volum, núm. 24 (4 d'agost de I837): 377.

Estaba el tio Musquerola ${ }^{48}$ molt repantigat en un banc del teatro vent com feen l'Otelo, y així que s'acaba de morir la so ${ }^{49}$ Delmira y el moro y caigué el teló, li preguntá Mauro el de la Conilla: —¿Qué t’ha paregut, Musquerola? ¿T'agradat la cosa? - No señor; no m'ha omplit del tot, perquè estaba aguardant que ixquera el grasios y el gran borinot no ha volgut eixir. - Pot ser que li hacha agarrat algun retorsó de ventre ú atra cosa, perque ell, de fijo, debia eixir. [...]

Tornaren atra nit al cap de temps y feren la comèdia de Más vale tarde que nunca. ${ }^{50}$ Estigueren tota la comedia en la boca uberta com qui empoma un buñol, ${ }^{5}$ y lo mateix: va ser caure la cortina, se planta Mauro una palmada en lo front y li diu al tio Musquerola: - Ya mos han engañat! Ara no ha eixit el moro a matar a la so Delmira!

Aplicació (elaboració pròpia): crítica als lectors d'El Mole que buscaven en el diari articles aliens a la seua essència i intencions. «En la comèdia buscaben morts, y en la trachedia grasios. ¿Qué tal? Pues lo mateix susuix en lo Mole a molts que no son llauradors. Perque no encontren en éll sermons y orasions de a full, diuen que no'ls agrá.»

\section{I4. [Sis coixos sense crosses]}

El Mole, ra època, 3r volum, núm. 4 (I9 d'agost de I837): 6I.

Anaben sis coixos, tots en closes, d'un poblet a un atre, y cansats de pegar cabotaes y ranclechar, ${ }^{52}$ s'asentaren baix d'un llidoner a tomar algun descanso mentre duraba la forsa del sol (perque asó susuí en lo mes de chuliol y es públic lo que calfa el sol). Els entrá la galvana ${ }^{53}$ y resolgueren pendre la siesta del borrego a la sombra del llidonero.

S'adorgueren els sis com a marmotes y, pasant per aquell closar uns que els coneixien, els ocurrí la inutilisadora idea de paralisar allí als pobres coixos amagantlos les closes, encara que no podien acostarse a ells de risa y bufits que pegaben els mal intensionats, de vore les cares tan insolents y falsificades que feen els coixos

48 Mosquerola: «Pera xicoteta, de color roig fosc en la part on toca el sol i verd groguenc en la resta, de carn granelluda i de gust dolç» (DNV).

49 So: Col-loquialment, senyora.

50 Más vale tarde que nunca: Comèdia de José Julián de Castro, autor teatral molt popular durant l'època. L'obra, ambientada a Hongria, incloïa efectivament un graciós en el personatge de Peregil.

5I Per a empomar un bunyol o atrapar-lo al vol hom necessita, òbviament, una gran obertura de la boca.

52 Ranquejar: «Anar ranc, caminar a la torta» (DCVB).

53 Galvana: Fam. 
(perque els coixos tenen la cara de gaidó, y la boca molt uberta cap a un costat cuant estan dormint.) Per fi, els amagaren les closes y pasaren avant.

Li pasá per lo cap al mes llech despertarse d'allí a poc y sinse estirar les cames (perque no podia de naixensa) s'asentá a mirar el sol per vore quin hora era. Ensomiant un atre, li pegá una galtá al que tenia al costat el despert. Obrí els ulls el de la bofetá, mes calent que un all, y veent als atres dormint, li emboca una puñá en los nasos al que estaba asentat. Este no sabia res, li pega un mochicó ${ }^{44}$ que l'atontá. S'agarren a reñir rodant per damunt dels atres y vátelos a tots cascanse la flor ${ }^{55} \mathrm{a}$ redolons y a rastrons, perque ningú es podia tindre dret, de modo que alló pareixia una riña de carabases y albudeques. ${ }^{56}$

Van a alsarse y veentse tots sinse les closes se quedaren fets d'alcheps (que sempre no ha de ser de pedra). Allí estigueren buscant a rebolcons les closes y ningú podia tornar a casa hasta que un troset mes aball repararen que un carreter, a qui se li habia romput una barra del carro y un tros de varal ${ }^{57}$ en un vuelco, buscant una rama grosa de garrofera per a empiularlo, ${ }^{58} \mathrm{~s}^{\prime}$ habia encontrat les closes amagaes y les estaba nugant al carro per a apañarlo. Y ú dels coixos, ya mes sosegat, li digué al carreter: -Amic, ¿Que eixes closes no tenen amo? Mire que eixes fustes, encara que son fustes, son cames.

Aplicació (extreta de l'original): «Els españols estan coixos; el gobern y la seua protecsió son les closes per a anar avant; si atre s'arregla en les nostres closes ó mos se les lleva, así estarem sinse móures y pegantse com els coixos sinse tindre ningú culpa.»

\section{I5. [L'ambaixador i la capa]}

El Mole, ra època, 3r volum, núm. 5 (23 d'agost de I837): 80.

Un embaixador franses, entrant en la audiensia de un Sultan, advertí que no li habien posat cadira per a obligarlo a estar dret. No estant de humor per a tindre les cames estirades, se llevá la capa tota bordada de or y plata, la doblá, la posá en terra y s'asentá molt «si siñor». Al anarsen se deixá allí l'embolic de la capa, y advertintli un turcot d'aquells que se l'enduguera, respongué: - Yo no acostume carregar en l'asiento.

Aplicació (extreta de l'original): «D. Carlos y comparsa fan lo mateix. No s'emporten l'asiento, si poden; pero s'enduen la casa y el poble, y si pogueren s'endurien la España en muntañes y tot a menchársela en pau y quietut en un rincó d'Italia.»

54 Motxicó: «Cop de puny a la cara» (DCVB).

55 Cascar-se la flor: Pegar-se (Martí Mestre 2006: I58).

56 Albudec: «Casta de meló xerec, aigualós, insípid.» (DCVB). La «riña de carabases y albudeques» fa referencia a l'espectacle que devien casusar aquells caps pegant-se arran de terra, sense poder alçar-se.

57 Varal: «Barra horitzontal dins de la qual van ficats els caps superiors de les estaques de la barana del carro.» (DNV).

58 Empiular: «Unir dos coses pels seus caps o extrems, empalmar-les» (DNV). 


\section{I6. [El papagai indiscret]}

El Mole, ra època, 3r volum, núm. 6 (26 d'agost de I837): 88.

En temps que hiabia frares aná ú dells a predicar en la festa de un poble, no me'n recorde de quin sant pero asó no importa que no se sapia perque no fá ni desfá a lo esensial de esta historia verdadera y fidedigna. Pará en la casa prinsipal del poble y despues de descansar la primera nit, al endemá se feu la festa y éll espetás9 son sermó com sabé y pogué.

Despues del sermó s'asentá segons costum al confesonari à recoger el fruto de la palabra de Dios. Acudí casi tot lo poble, en particular chovenalla utriusque sexus, ${ }^{60}$ que tenien reparo de confesarse en lo pae retor. En fi, lo que el bon frare s'oui raere de la reixeta no ho conta la historia, pero sí conta que en acabant se n'aná a la casa-aloixament, se ficá en el cuarto mes calent que un all y les orelles com a dotrinetes, ${ }^{6 \mathrm{II}} \mathrm{y}$ en un bell rato no pará de dir... — ¡Chesús! ¡Chesús! ¡Chesús! ¡Tantes y totes p...! ¡Tants, y tots cab...!

Per casualitat hi habia en una gabia en el balcó de la sala un papagall molt parlaor y de molt talent que no pillaba paraula que no la repetira. Pasá la cosa y d'allí a un rato entra tota la faramalla de achuntament, notabilitats, siñores, etc a donarli la n'horabuena al pae predicaor y preguntarli si s'habia cansat etc. Prenguéren asiento y comensá la tertulia, pero vechen vostedes per aon li ocurrix al malait papagall ficar la cullerada y, cuant manco se pensaben, se posá a cridar en aquella veu de caña badada: ${ }^{2}$ — ¡Tantes y totes p...! ¡Tants y tots c...!

No es per a dir la chilladisa que es mogué: l'ama de casa, tota afrontada, ${ }^{63}$ volgué donar una satisfacsió a la tertulia y alsantse de la cadira digué:-Anem a dinar, que está ya la taula parada, y no fasen cas de eixe animal, que es un loco. -Aténgome - respongué ú de la concurrensia- a que los niños y los locos dicen las verdades, segun canta el refrán.

Aplicació (elaboració pròpia): Dubtosa. Sembla apel-lar-se a la necessitat que El Mole siga sempre fidel a la veritat, com els xiquets, els bojos o els lloros.

59 Espetar: Sembla un castellanisme. «Decir a alguien de palabra o por escrito algo, causándole sorpresa o molestia» (DRAE).

6o Utriusque sexus: D'un sexe i de l'altre.

6I Tindre les orelles com doctrinetes: No hem trobat el significat d'aquesta expressió que, per altra banda, sembla testimoniar-se no sols a València sinó a Tortosa. Pel context, hom pot imaginar que parla d'orelles roges o teses.

62 La canya badada s'ha usat tradicionalment al País Valencià com a instrument musical. Percudida, genera un so semblant al clac-clac-clac característic dels lloros.

63 Afrontar-se: Avergonyir-se (DNV). 


\section{Conclusions}

Amb aquest article hem mirat d'editar i rescatar de l'oblit uns textos que, inserits dins la revista $E l$ Mole, representen, al nostre parer, una de les mostres més antigues de contes valencians de tradició oral, i un exemple de material folklòric preexistent a l'inici de les grans recopilacions del segle XIx. Al llarg dels apartats inicials hem aportat proves i indicis que demostren el caràcter folklòric dels textos antologats. Després, hem raonat, amb les aplicacions, com els editors empraren aquest material amb el propòsit de fer més planer el seu objectiu proselitista, lligat a l'expansió de les idees liberals a través d'una classe social, la camperola, susceptible de caure en les mans de la propaganda carlina.

Comptat i debatut, els redactors d'El Mole, talment com feien els predicadors medievals amb els exempla, reutilitzen un material de natura folklòrica presentant-lo en clau doctrinal; millor dit ací, ideològica. En ambdós casos la captatio benevolentiae obligava no sols a adoptar un llenguatge entenedor per a les masses, sinó també a la utilització d'uns referents coneguts i lligats d'alguna manera a la memòria col-lectiva, en aquest cas petites històries que de segur el llaurador valencià del XIx havia sentit recitar moltes vegades a la llar. En el fons, es tractava de modelar l'opinió del lector adaptant-se al seu llenguatge i al seu món de referències.

Ja dins l'estudi immanent dels textos, hem pogut observar com hi concorren formulismes propis del narrador tradicional i, alhora, tòpics arreplegats pels principals catàlegs. Hi destaquen les històries basades en confusions lingüístiques, reflex del context diglòssic de la València contemporània, i també les basades en duels d'enginy. No és cap casualitat: els dos tipus de relat faciliten una contraposició de personatges que s'adequa al maniqueisme de tot discurs ideològic i en particular a l'exaltació del tercer estat, tan típica del liberalisme: per una banda, la contraposició valencià/castellà permet l'estranyament de l'altre entés com a membre d'unes elits que se senten alienes; per l'altra banda, el fet que en alguns contes el personatge humil, generalment el llaurador, destaque pel seu enginy, subratlla la sintonia que El Mole buscava amb els menestrals, i reforçava l'autodiscurs d'aquests.

Així, doncs, la superposició entre el conte original, l'aplicació ideològica que hi afegim i la visió que aporta aquest article ens permet d'entendre cada conte en el triple espill que ofereixen l'origen folklòric remot, el tamís ideològic del segle xIx i la nostra mirada de lectors del segle XXI. 


\section{Referències bibliogràfiques}

BALAgUer, Enric (I988): «Una revista popular valenciana: El Mole (I837 i I8404I)». Caplletra. Revista internacional de filologia núm. 4: 69-78.

BELTRAN, Rafael (2007): Rondalles populars valencianes: Antologia, catàleg i estudi dins la tradició del folklore universal. València: Publicacions de la Universitat de València.

Bordería, Enrique; Francesc Martínez Gallego; Inmaculada RiUs (2004): Política, cultura y sátira en la España isabelina: José Bernat y Baldoví. València: Institució Alfons el Magnànim.

BORJA, Joan (20I3): «Els relats humorístics d'arrel lingüística: consideracions a propòsit del tipus ATU I699 ("Malentesos entre parlants de diferents llengües")». Estudis de Literatura Oral Popular núm. 2: 45-73. DOI: https://doi. org/IO.I7345/elop2OI345-73.

[DCVB] Diccionari català-valencià-balear. Institut d'Estudis Catalans / Editorial Moll. <http://dcvb.iecat.net/> [data de consulta: febrer de 20I8].

[DNV] Diccionari normatiu valencià. Acadèmia Valenciana de la Llengua. <www. avl.gva.es/lexicval> [data de consulta: febrer de 20I8].

[DRAE] Diccionario de la Real Academia Española. Real Academia Española de la Lengua. <http://dle.rae.es/> [data de consulta: febrer de 20I8].

Hernández, Ángel (20Io): Catálogo tipológico del cuento folklórico en Murcia. Madrid: El Jardín de la Voz.

LAGUNA, Antonio; Eduardo ORTEGA (I989): Un periodista romántico en la revolución burguesa: José María Bonilla. València: Asociación de la Prensa Valenciana.

MARTí GADEA, Joaquim (I89I): Ensisam de totes herbes o ensart de cansons valencianes y castellanes. València: Impremta de Josep Canales Romà.

MARTí MeStRE, Joaquim (2006): Diccionari històric del valencià col-loquial. València: Publicacions de la Universitat de València.

MenAges, Àngela-Rosa; Joan-Lluís Monjo (2007): Els valencians d'Algèria (I83OI962). Memòria i patrimoni d'una comunitat emigrada. Picanya: Edicions del Bullent.

PÉrez, Jaume (I998): «Prosa narrativa de la Renaixença al País Valencià: "El Mole”, "La Donsayna” i “El Tabalet”». Estudis: Revista de historia moderna núm. 24: 449-466.

ThOMPSON, Stith (I955-I958): Motif-index of folk-literature. A classification of narrative elements in folktales, ballads, miths, fables, medieval romances, exempla, fabliaux, jest-books and local legends. København / Bloomington: Indiana University Press.

UTHER, Hans-Jörg (2004): The types of international folktales. A classification and bibliography. 3 vols. Folklore Fellows' Communications 284-285-286. Hèlsinki: Suomalainen Tiedeakatemia. 